\title{
The Technology for the Development of the Officers' Conflictological Competence
}

\author{
Aigul Abdimazhitovna Bulatbaeva ${ }^{1}$, Vladislav Vladimirovich Luchinin ${ }^{2}$, Zhusupov Serik Khasanovich ${ }^{3}$, \\ Ospankulov Ernar Erlanovich ${ }^{4} \&$ Baygaliev Adilbek Manarbekovich ${ }^{4}$ \\ ${ }^{1}$ Al-Farabi Kazakh National University, Kazakhstan \\ ${ }^{2}$ The Frontier Academy of the National Security Committee of the Republic of Kazakhstan, Almaty, Kazakhstan \\ ${ }^{3}$ Kazakh Leading Academy of Architecture and Civil Engineering, Almaty, Kazakhstan \\ ${ }^{4}$ Kazakh National Pedagogical University Abay, Almaty, Kazakhstan \\ Correspondence: Baygaliev Adilbek Manarbekovich, Al-Farabi Avenue, 71, Almaty, 050040, Kazakhstan.
}

\author{
Received: December 27, 2014 Accepted: March 20, 2015 Online Published: May 22, 2015 \\ doi:10.5539/ass.v11n14p70 URL: http://dx.doi.org/10.5539/ass.v11n14p70
}

\begin{abstract}
The present article is devoted to the essence of the problem of development of the conflictological competence of a modern officer. The authors have considered understanding of the conflict, conflictological competence of an officer, its constituent components, studied the causes of conflicts in military formations. The place and role of the conflictological competence in the structure of professional competence of an officer, as well as its impact on the effectiveness of administrative functions implemented by military leaders, have been determined. The article provides an overview of the results of the survey carried out among the officers in order to determine the extent of development of their conflictological competence. The content and mechanism of implementation of the technology for the development of the conflictological competence of military leaders have been provided.
\end{abstract}

Keywords: conflictological competence, professional competence, management activities, technology, problem-project approach.

\section{Introduction}

\subsection{Introduction to the Problem}

Successful modernization of the Armed Forces, other troops and military formations of the Republic of Kazakhstan is largely dependent on the competence of officers with high intellectual potential, competent and qualified specialists who know their business well. The military readiness and the fate of changes entirely depend on the officer corps, which is the golden fund of the Army (Military Doctrine of the Republic of Kazakhstan, 2011).

In Kazakhstan the system of planning of the officers' career, providing for the rotation of the service out of the command duty in the Armed Forces and into the post in the staff headquarters and out of the staff headquarters into the command duty, the rotation of troops, which provides an opportunity for officers to develop multi-faceted skills, as well as to prevent "stagnation" of military staff, has already been established. Since 2012 officers have been appointed to senior posts on a competitive basis, which is a fundamental difference from the previously operating system. Officers, listed in the officers reserve for nomination to the posts, can be considered as candidates for appointment. The certification of officers is held every three years. On the basis of the certification the reserve list of officers for nomination to senior posts and training assignments are made (News as of 23.10.2013).

\subsection{Updating the Issue of Development of the Officers' Conflictological Competence}

Given the specificity of military service, the suddenness and unpredictability of the situation, it can be stated that the officers' management activities are difficulty-combining ones and have an extreme character. The effectiveness of the service and army activities of the military organization as a whole depends on the productivity of the management of military leaders at all hierarchical levels.

It should be noted that the activities in the "man-man" system requires leaders' compliance of certain duties aimed at adjustment of the processes of professional interaction between the subjects of military service, 
resolution and transformation of conflicts of different levels of complexity. Tragic events entailing the loss of personnel (events happened on the post "Arkankergen", etc.), necessitate taking a new look at the problem of professional military leader, as well as reconsidering currently cultivated approaches to officers' training in this direction. The main research efforts in the psychology of management are focused on optimizing staffing activities, resolving problems that can occur during the professional interaction between military leaders and subordinates, positive regulation of intra-group interpersonal relations and enhancement of professionalism in the work of the management staff. In this regard, the present article shall consider the state of the problem and features of the technology for development of the officers' conflictological competence.

\subsection{What Is a Conflict in Our Understanding?}

The definition of a conflict includes any situation in which people have incompatible interests, goals, principles and feelings. Conflicts often arise in organizational contexts where there are interdependent relationships (Runde \& Flanagan, 2010; Fick-Cooper \& Baker, 2011).

In some studies, a conflict is characterized as a socio-psychological phenomenon and it is emphasized that it can be not only a destructive factor, but it can also act as a factor of changes, a source of innovations and an impetus for rethinking life scenarios (Boulding, Giddens, et al.). Kozer L. considers a conflict as a "fight for the values and aspirations for a certain status, power and resources, in which the aims of the opponent are to neutralize, damage or remove the opponent". Accordingly, this author assumes that a conflict is an essential element of social interaction that contributes to strengthening or destruction of social ties (Coser, 2000).

We consider the conflict from the point of view of management, i.e. the importance of converting the negative, destructive consequences of the conflict into constructive possibilities. The conflict in the most general terms means specifically organized activities in which the contradiction is held in the process of its resolution.

\subsection{An Impact of the Conflict on the Quality of Management Activities}

A number of authors who have studied an impact of the conflict on the process of management activities, state the following:

- One of the main criteria for assessing the ability of a manager to implement management activities is his/her willingness to deal effectively with non-standard problematic situations, bearing the controversial nature (Kudryashova, 1983);

- For the effective management in unusual situations it is important to have the skills of constructive communication during acute conflicts (Derkach \& Scherbina, 1998);

- The ability to act in conflict situations is an important professional skill of a manager (Perminova, 1997);

- In most cases conflicts have a negative impact on the entire organization, as they can adversely affect the emotional state of managers (Chervony, 2013);

- A negative impact of conflicts on the organization's activities is a significant diversion of the manager's efforts from the solution of the main administrative tasks, as they require additional resources for resolution of conflict situations.

\subsection{On the Conflictological Competence}

The implementation of professional functions occurs in three interrelated processes: interaction, communication, relationship. The concept of interaction suggests the presence of different interacting parties and the actions between these parties should be inter-directed and interdependent, i.e. parties should regulate the process of the conflict (Grishina, 2000).

John Raven refers the ability to resolve conflicts and mitigate differences to the main competencies of a person (Raven, 2002).

Zazykin V. G., Bogdanov E. N. indicate that the lack of conflictological competence is one of the most important psychological causes of the conflict (Zazykin \& Bogdanov, 2004).

Shepel V. M., considering the activity of managers in special circumstances, highlights "managerial communication skills in an acute situation" of a technical and organizational type that reduce the aggressiveness of the parties and the creation of conditions for a constructive dialogue (Shepel, 1984).

The conflictological competence is regarded as a kind of the social-psychological competence (Antsupov \& Shipilov, 1999, p. 491). Hasan B. I. expanded the concept of the conflictological competence, considering it as one of the leading characteristics of a person and an important part of the overall communicative competence, 
which is a level of awareness of the range of possible strategies of behavior in a conflict and skills to implement these strategies in specific situations (Hasan, 2003).

\subsection{Comparison of the Concepts of "Conflict" and "Conflictological" Competence}

The comparative content analysis of the concepts of "conflict" and "conflictological" competence allows to safely assume that between them there are no fundamental differences, there are only minor differences on some components (Khudayeva, 2007).

At the "special" level in the content of the conflictological competence the following differences from the conflict competence can be indicated:

- Greater focus on the anticipation of opponents actions in conflict situations;

- There is a willingness to comply with ethical norms and follow the requirements of professional management culture in the process of conflict management;

- The presence of motivational affirmation of management subjects on the desire to improve one's conflictological preparedness, promoting the conflict-free organization of professional activities.

In general, the conflictological competence can be considered on two levels. The first level involves the ability to recognize the signs of the conflict occurred, its registration in order to keep the contradiction containing in this conflict and possession of regulation methods for its resolution.

The second level provides the ability to design some conflicts necessary to achieve certain results and construct them in situations of interaction; it is necessary to possess the ways of organizing productively oriented conflict behavior of participants and parties of the interaction.

\section{Methods}

\subsection{Conflicts in Military Units}

It should be noted that the number of conflicts in military units is relatively non-public information, and the available data are approximate and based on open sources and expert assessments.

Kalyuzhny A. S., exploring features of conflicts in Russian military units, has distinguished three types of conflicts: the conflict that arises between individual soldiers is an interpersonal conflict; a "vertical" conflict occurs between the subordinate and the supervisor; intergroup conflicts occur when groups of individual soldiers act as the warring parties, not individual soldiers. A typical intergroup conflict in the unit is a conflict between two groups of soldiers of different years of military conscription or conflicts arising on ethnic grounds. Moreover, studies carried out by Kalyuzhny A. S. in 2003-2004, namely the analysis of 250 conflicts in the Army and Air Defense Forces, show that the most frequent conflicts between officers in relations "subordinate - immediate commander" amount to $48 \%$ of all conflicts occurred. Another $30 \%$ of conflicts occur in relations "subordinate direct commander". $19 \%$ of the total number of conflicts occur between the officers who are not linked by relations of subordination, while $3 \%$ - between temporarily subordinates. This implies that the typical conflict for officers in the unit is a conflict with their subordinates or commanders. The analysis of a large number of real conflicts showed that approximately $70 \%$ of conflicts were initiated by a soldier (Kalyuzhniy, 2004).

\subsection{The Author's Understanding of the Nature and Structure of the Officers' Conflictological Competence}

We consider the conflictological competence of an officer as a integrative property of officer's personality with a set of theoretical knowledge and practical skills in the sphere of conflict resolution, corresponding to the requirements of professional qualifications and contributing to internal mindset on conflict-free and expedient actions in different conditions of interpersonal interaction, defined by a high conflictogenic potential of the working environment.

The structural components of the conflictological competence of an officer are as follows:

- Gnostic component (knowledge on the reasons for the conflicts occurrence, features of their development, opponents' behavior, mental states, etc.);

- Regulatory component (the ability to provide a constructive impact on the assessment, motives and attitudes of the opponents; manage the conflict at all stages of its deployment; mediation);

- Projecting component (the ability to anticipate the actions of one's opponents in conflict situations);

- Communicative component (the ability to carry out effective communication with due regard to personal characteristics and emotional states of the opponents); 
- Reflexive-status component (an adequate response to the contradictions occurring in the course of interpersonal interaction, the ability to gain self-knowledge);

- Normative component (knowledge on the regulatory and moral regulators of behavior in conflict situations, the possession of professional management culture, a willingness to comply with ethical requirements);

- Motivational component (willingness to develop and improve one's conflictological knowledge and skills).

\subsection{Research Tool}

For the analysis of the real state and the practice of development of officers' conflictological competence the survey was conducted among active duty officers and reserve officers. The active duty officers were given a questionnaire consisting of 25 confidential questions by three blocks: the assessment of officers' knowledge on the conflict and the ways of its resolution; the nature of the most frequently occurring conflicts; conditionality of the management quality as far as the officer's conflictological competence is concerned. The reserve officers were given a questionnaire consisting of 21 confidential and open questions by the following blocks: the assessment of the development of the officers' conflictological competence in the Army and military units; proposals for the development of the conflictological competence.

The test on determining the dominant strategies of conflict behavior (metaphorical version) has also been conducted. The task was to assess the degree of using the proposed sayings in one's behavioral practice. In accordance with the ratio of two dominant goals reflecting the commitment to "oneself" and "interaction with others", metaphorical strategies of conflict behavior can be indicated.

\section{Results}

The total number of the study participants amounted to 100 officers and 20 reserve officers. The study participants were men (88\%) and women (12\%). The age of participants varied from over 45 years old $-17 \%$; $36-45$ years old $-30 \%$; $26-35$ years old $-31 \%$; $18-25$ years old $-22 \%$. Work experience included more than 10 years $-16 \%$; from 1 to 3 years $-19 \%$; from 3 to 7 years $-28 \%$; $7-10$ years $-19 \%$, up to a year of work experience $-18 \%$. All participants had a higher education.

\subsection{Active Duty Officers Questioning}

Almost $94 \%$ of the officers noted that these or other conflicts in the course of management activities of the officers were practically inevitable, while $65 \%$ assumed that conflicts had a negative impact on the effectiveness of management activities of the officers and morale of the military staff. As typical consequences of management conflicts they distinguished the following: bias and formalism in relations between the military staff; subordinates artificially create problems connected with service and social life; extremely hindered interpersonal communication.

In the result of ranking causes of conflicts between managers and subordinate officers we put the excess of the official authority on the first place; the humiliation of honor and dignity of subordinates appeared on the second place; giving illegal orders appeared on the third place.

According to the respondents, the majority of conflicts occur at the level of "officer-officer" and "officer-commander - contract serviceman (non-management soldiers, etc.)" (59\% of the respondents). $63 \%$ of the officers offer targeted training and improvement of the level of the officers' conflictological competence as a means of conflicts prevention. While $83 \%$ of respondents noted the need to develop a constructive component of conflictological competence (skills in conflict management at all stages, especially the settlement and constructive resolution of conflicts).

\subsection{Reserve Officers Questioning}

These results are also confirmed by the results of the survey of reserve officers. $67 \%$ of reserve officers evaluated the level of conflictological competence as an average one. $46 \%$ of respondents assume that the main cause of the conflicts is that administrative officers adhere to the following position: the organization and control are the main factors while the human factor is a secondary one.

Respondents noted that the low conflictological competence was accompanied by rigidity, formalism of relations, low emotional stability, low communicative culture, low self-esteem of an officer. As possible effects of low-level conflictological competence of the officers $33 \%$ of respondents noted a decrease in staff morale, $27 \%$ of respondents noted a decrease in the authority of an officer and its impact on subordinates and $27 \%$ of respondents noted a decrease in the management efficiency and the quality of the work of subordinates. 
All respondents noted the need to include conflictological discipline in the curriculum of post-graduate students training and advanced officers training.

\subsection{Survey Results}

Processing of the survey results has shown that most of active duty officers (54\%) assume that conflicts are resolved only when one of the parties wins, while the second one loses, $8 \%$ of managers assume that relationships are important and they can sacrifice the goals; $13 \%$ of respondents are willing to give up any part of the goals to maintain the relationships, and only $25 \%$ of respondents assume that it is necessary to work together to achieve the goals, seek to find solutions that can satisfy all the parties.

Table 1. Characteristics of the survey results

\begin{tabular}{lll}
\hline Strategy & Characteristics & A number of respondents (of 100) \\
\hline "Turtle" & The strategy of going under one's shell & - \\
"Shark" & Force strategy & 54 \\
"Bear's cub" & Strategy of accommodation of conflicting situations & 8 \\
"Fox" & Strategy of compromises & 13 \\
"Owl" & Strategy of direct and honest confrontation & 25 \\
\hline
\end{tabular}

\section{Discussion}

\subsection{Discussion of the Most Frequent Factors of Conflicts Occurrence}

Thus, the survey results allow to identify the most common objective and subjective causes of conflicts. The objective causes are as follows: 1) the majority of conflicts are connected with the violation of the system of interpersonal relationships that occur as a result of the transfer to the reserve, and different level of commanders' insistence on implementation of the service in general and combat training; 2) young newcomers-commanders have conflicts with subordinates 3 times more often, and most often these conflicts occur in the first 3-4 months of working on a new position; 3) low elaboration of legal and other regulatory procedures for resolution of interpersonal conflicts that arise in relations between service members. Subjective causes of conflicts are as follows: 1) bias, low communication skills and lack of knowledge how to resolve conflicts; 2) the desire to assert his own authority at any cost; 3 ) high self-esteem of a service member, etc.

\subsection{Discussion of the Survey Results}

The practice of military activities shows that it is impossible, relying only on the directive and administrative postulates, to improve the quality of management over military units. Military staff is a living organism that exists according to certain laws and regulations that are often not spelled out in the training literature. Managers do not have sufficient administrative and life experiences, they experience serious difficulties in the process of building relationships with subordinates, especially with contract servicemen serving on positions of soldiers and sergeants. Prolonged emotional stress affects the moral and psychological atmosphere of units, conflicts on the background of such stress significantly disrupts the activities of the military organization.

The results of the survey show that in extreme situations most of managers are not able to effectively cope with emotional stress, in this connection, the administrative impact is usually carried out in a fit of emotions, superficially and with lack of judgment. Stereotypes of the actions in conflict situations, enshrined in the informal rules of behavior, make less experienced managers to commit rash acts that sometimes end in negative consequences.

\subsection{Discussion of the Existing Models of the Conflictological Competence}

Craig E. Runde, while studying an individual model of the conflictological competence, provides that people are able to calm down, manage their emotions, slowly go out and think about what is going on, and then interact constructively with others to solve this problem (Runde, 2014). The phase of calming down allows people to regain composure. Without this balance, it becomes too difficult to manage one's behavior, the situation is stirred up and this causes a negative reaction of another person.

It is therefore proposed to study the Conflict Dynamics Profile (CDP), this is a tool to assess behavioral patterns that people use in conflict situations. CDP measures are the frequency with which people use seven constructive responses (perspective of making decisions, creating solutions, expression of emotions, drawing, reflective thinking, delayed responses to requests and adaptation) and eight signs of destructive behavior (win at all costs, 
expressing anger, humiliation of others, retribution, avoidance, compromise, hiding emotions and self-criticism) (Capobianco, Davis, \& Kraus, 2001). Knowing these behavioral patterns can influence and effectively manage conflicts.

\subsection{Problem-Project Technology of Development of the Officers' Conflictological Competence}

Development of the technology that combines problematicity and practical activities of students, allows to significantly increase the degree of assimilation of training material, as in the search for solutions of the problematic tasks the students' intellectual activity is being activated, with maximum mobilization of their intellectual abilities (Bulatbaeva, 2009). Internalizing the information received during the training process, the trainees have the opportunity to externalize this knowledge into practical skills, bringing them in practice to a significant level of development.

The content of the technology determines the sequence of trainees' actions on solving the problematic situational and practical tasks in a professional context. This technology represents a theoretical and practical training course consisting of 15 hours ( 1 credit) and covers the following sections: a) conflict prediction; b) conflict prevention; c) conflict promotion; g) conflict resolution; e) conflict settlement.

The technology provides for the phased implementation of the project tasks, with further defense of the developed algorithms for the actions of military leaders in various interpersonal situations having a potentially conflictogenic orientation.

\subsection{Description of the Course Aimed at the Development of the Conflictological Competence}

The content of the special course is aimed at the development of the causes of interpersonal conflicts and conflict situations between the military; features of human nonverbal behavior and interpretation of his/her signals; methods for forming up constructive communication in the process of interaction with opponents and influencing their behavior; the analysis of existing types of conflicting personalities and their individual psychological characteristics, etc.

As an information support the trainees are offered materials that allow the students to implement the adaptation of their behavior and the behavior of suspected opponents in pre-conflict and conflict situations, as well as to manage their behavior in a dynamically growing conflict.

\subsection{Characteristics of Stages of Development of the Conflictological Competence}

A preliminary or motivational stage involves conducting communication training, as well as the solution of various cognitive tests and crosswords. The content of these tasks is the theoretical thesis from the sphere of conflict resolution, revealing the key provisions and relating to a particular lesson. The main purpose of this stage is the creation of a positive motivational setting of trainees.

The main stage, in its turn, is subdivided into sub-stages: analytical and practical ones. Analytical sub-stage is aimed at identification of contradictions in the situation under consideration, the formation of the problem, hypothesis and assignment of tasks. Students' independent work on identification of existing contradictions in the situation and the formation of the problem are the essence of this stage and meets the requirements of high problematicity. Practical sub-stage provides independent project activity of the students in groups of 3 persons, followed by defense of the developed algorithms that reveal the process of solving a problematic situation.

The content of the final stage is aimed at summarizing results of the lesson, evaluating the results of the trainees, the formulation of the basic principles of managers in similar situations.

\section{Conclusion}

Conflicts in the military professional environment divert significant moral, psychological and material resources, violate internal emotional background, disrupt the activities of the staff, subject its employees to a negative psychological impact. In this regard, the officers' possession of competence in the sphere of conflict management, optimizes interpersonal interactions and creates the preconditions for the growth of efficiency of administrative processes. Given the focus of the conflictological competence on maintenance of the optimal interaction between people, building constructive relationships and overcoming barriers in interpersonal communication, this competence can be confidently attributed to one of the main components of the professional competence of an officer.

In our opinion, the developed technology can provide sufficient motivation of students to assimilate the content of the training material as it affects important aspects of their professional activities and meets their cognitive interests. Students' theoretical understanding and independent practical solution of complex situational tasks taken directly from the experience of the professional activity, and perhaps not quite wisely solved by them in 
the past professional activity, can strengthen their cognitive activity, thereby increasing the level of assimilation of theoretical and practical parts of the training material.

\subsection{Recommendations}

In conclusion, we would like to make the following recommendations for the development of the officers' conflictological competence:

1. The purposeful work on education of the officer personnel before the appointment to positions shall be organized; development of the officers' conflictological competence through the technology based on the problem-project training, helps to optimize the management activities of the military leaders.

2. The optimal area of application of the problem-project technology in the development of the conflictological competence is the process of attending advanced officer courses by military leaders, professional training of the officers, as well as optional training courses of senior cadets studying in military universities.

\subsection{Prospects}

Due to the departmental subordination and the privacy of some military units and formations, we failed to make a more ambitious evaluation procedure of the level of the officers' conflictological competence and test the developed technology.

In prospect we would like to make a comparative analysis of the level of formation of the officers' conflictological competence in various military formations, identify the most general and specific conflictogenic components in military-professional environment and develop a series of training programs to enhance the conflictological competence of future officers.

\section{Acknowledgement}

The authors express their gratitude to the management of the Border Service Academy of the National Security Committee of the Republic of Kazakhstan for the opportunity of testing the technology of development of the officers' conflictological competence on advanced courses, to the Professor Abraimov D.K. and the General Asylov N. J. for professional comments and qualitative discussion of the content of the workshops, training and project material we offered.

\section{References}

Antsupov, A., \& Shipilov, A. (1999). Conflict management: Textbook for universities. Moscow.

Bulatbaeva, A. (2009). The methodology of research activities of a graduate student: Theory and Practice. Almaty.

Capobianco, S., Davis, M., \& Kraus, L. (2001). Conflict Dynamics Profile - CDP 360 Slide Show. Retrieved February 28, 2014, from www.conflictdynamics.org/cdp/download.php

Chervony, P. (2013). Formation of the conflictological competence in educational work with students of the Ukraine MIA. Alma mater. Series: Pedagogy and Psychology, 2, 71-75.

Coser, L. (2000). Functions of the social conflict. Moscow: "Idea-Press" Publishing.

Derkach, A., \& Sherbina, A. (1998). Effectiveness of the executives in the management of extreme situations. Moscow: MPAKTS.

Fick-Cooper, L., \& Baker, E. (2011). The Management Moment: Building Conflict Competence. Journal of Public Health Management \& Practice, 17(2), 187-189. http://dx.doi.org/10.1097/01.PHH.0000394666. 06764.5a

Grishina, N. (2000). Psychology of the conflict. Saint-Petersburg.

Hasan, B. (2003). Constructive psychology of the conflict. Saint-Petersburg: Piter.

In Kazakhstan a national system of military personnel training has been formed. (2013, October 23). News. Retrieved February 28, 2015, from http://www.zakon.kz/4582555-v-2018-godu-vvp-na-dushu-naselenijav.html

Kalyuzhniy, A. (2004). Conflicts in military units: Textbook. Nizhny Novgorod: NSTU.

Khudayeva, M. (2007). Psychological conditions of the conflictological competence in adolescence. Synopsis of a thesis. Belgorod. Retrieved December 22, 2014, from http://diss.rsl.ru

Kudryashova, L. (1983). Systemic psychological evaluation of management personnel and management systems. Kishinev: Shtiintsa. 
Military Doctrine of the Republic of Kazakhstan. Presidential Decree of the Republic of Kazakhstan No. 161. (2011, November).

Perminova, I. (1997). Optimization of organizing activity of the management personnel in special circumstances. Synopsis of a thesis. Moscow: RAGS. Retrieved April 13, 2014, from http://diss.rsl.ru

Raven, J. (2002). Competence in modern society: its identification, development and implementation. Trans. from English. Moscow: "Cogito Center".

Runde, C. (2014). Conflict Competence in the Workplace Employment Relations Today. http://dx.doi.org/10.1002/ert.21430

Runde, C., \& Flanagan, T. (2010). Developing Your Conflict Competence: A Hands-On Guide for Leaders, Managers, Facilitators, and Teams Hardcover.

Shepel, V. (1984). Managerial Psychology. Moscow: Economics.

Zazykin, V., \& Bogdanov, E. (2004). Psychology of a person in the conflict: the manual (2nd ed.). Saint-Petersburg: Piter.

\section{Copyrights}

Copyright for this article is retained by the author(s), with first publication rights granted to the journal.

This is an open-access article distributed under the terms and conditions of the Creative Commons Attribution license (http://creativecommons.org/licenses/by/3.0/). 